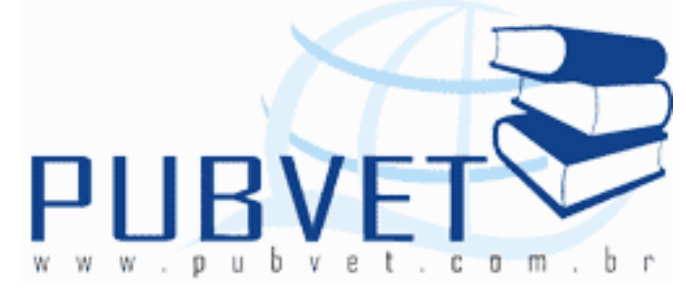

PUBVET, Publicações em Medicina Veterinária e Zootecnia.

\title{
Viabilidade do fornecimento de água e ração para leitões em lactação no sistema Wean to finish
}

\section{César Augustus Winck ${ }^{1}$ e Cristiano Leite de Godoy ${ }^{2}$}

1 Doutor em Agronegócios (CEPAN/UFRGS) e Professor da UNOESC. cesar.cepan@gmail.com

${ }^{2}$ Engenheiro Agrônomo (UNOESC)

\section{Resumo}

O sistema de produção de suínos conhecido mundialmente como Wean to Finish vem se tornando uma alternativa interessante para melhorar resultados econômicos e técnicos da suinocultura brasileira. Esse sistema consiste basicamente em transferir a fase de produção conhecida como creche diretamente para o local onde os suínos irão permanecer durante a sua fase de recria e engorda, ou seja, no dia do desmame os suínos já são alojados no local onde permanecerão até o abate, eliminando as fases intermediárias. Essa nova forma de produção é pouco conhecida no Brasil, e com a implantação do sistema, várias adaptações são necessárias, pois os modelos utilizados em outros países não atendem as necessidades do sistema nacional. Considerando que o alto peso dos leitões no desmame se torna um requisito indispensável, algumas medidas foram tomadas, como a alteração nos conceitos de nutrição de matrizes e na idade do desmame. O objetivo desse trabalho foi consolidar o conhecimento a respeito do sistema Wean to finish, utilizando a metodologia 
de fornecer suplementação (ração e água) a leitões durante a fase em que os mesmos estão sendo amamentados, e os resultados obtidos foram que durante a fase de amamentação, os leitões que receberam suplementação com água e ração não demonstraram benefícios comparando com os que não receberam, porém o fornecimento de água foi benéfico para o ganho de peso inicial do leitões, impactando na fase subsequente (creche/terminação). Conclui-se que a suplementação nutricional com água e/ou ração, avaliando-se apenas a fase de lactação dos leitões não se torna viável, mas o fato dos leitões já estarem adaptados aos bebedouros instalados, aparentemente melhora o desempenho na fase subsequente da criação de suínos.

Palavras-chave: Peso ao desmame, Idade de desmame, suplementação com ração, suínos.

\section{Viability of water supply and feed for lactating piglets in Wean to finish system}

\section{Abstract}

The system of pig production worldwide known as Wean to Finish has become an interesting alternative to improve economic and technical results of Brazilian pig production. This system basically consists in transferring the production phase known as day care directly to where the pigs will remain during their rearing and fattening, is on the day of Weaning pigs are now housed at the site where they will remain until slaughter eliminating the intermediate phases. This new form of production is little known in Brazil, with the deployment of the adaptations were necessary because the models used in other countries did not meet the needs of the national system. The high weight of piglets at Weaning becomes an indispensable item. Therefore, some measures were taken, such as changing concepts of nutrition and dies at the age of Weaning. The aim of this work is to consolidate the knowledge about the system Wean to finish, using the methodology of providing supplementation (food and water) to piglets during the phase in which they are 
being breastfed, and the results were that, during the breastfeeding, piglets that received supplementation with food and water showed no benefit compared with those who did not, but the water supply was beneficial for piglets torn during the subsequent phase (nursery/finishing), so it follows that nutritional supplementation with water or feed only evaluating lactation piglet is not feasible, but the fact of knowing the pigs trough causes them to obtain better performance in the subsequent phase.

Keywords: Weaning weight, Weaning age, diet supplementation, pigs.

\section{INTRODUÇÃO}

A suinocultura é importante para o agronegócio brasileiro, pois além de ser a principal atividade em muitas propriedades rurais, movimenta grandes valores financeiros no mercado interno e com exportações. Porém essa atividade sofre com constantes oscilações de mercado e, consequentemente, de preços. As chamadas "crises da suinocultura" estão se tornando mais duradouras e agressivas, tendo como reflexo imediato, a transferência da atividade para grandes propriedades, e a descapitalização do pequeno e médio produtor.

A alternativa para a sobrevivência da suinocultura brasileira está na busca por novas tecnologias, tornando a atividade mais eficiente, reduzindo custos, melhorando o desempenho e produzindo com foco na sustentabilidade. Frente a esta mesma situação, a suinocultura norte-americana sentiu a necessidade de melhorar seu sistema de produção, e com isto, acabou por se desenvolver o sistema conhecido mundialmente como Wean to Finish, que consiste basicamente em eliminar uma fase da produção, sendo esta a fase de creche, e portanto, os animais são alojados nas instalações de terminação no momento do desmame.

O sistema Wean to finish vem se consolidando como alternativa interessante para aumento da rentabilidade e, em alguns casos, viabilizando a suinocultura de muitos países. Desenvolvido nos Estados Unidos, esse sistema 
revolucionou a suinocultura americana, permitindo se destacar no cenário mundial, mesmo sobre condições adversas como temperaturas extremas e grandes desafios sanitários.

Para a implantação deste sistema no Brasil, diversas adaptações tiveram que ser realizadas no sistema produtivo, pois o modelo americano não alcançou resultados esperados no país. Diversas dúvidas e questionamentos sobre o manejo dos suínos surgiram e, algumas respostas já foram alcançadas, podendo-se citar a necessidade de desmamar leitões com alto peso, mesmo que para isso alguns conceitos e tendências tenham que ser desmistificados, como o desmame de leitões com idade média de 28 dias, enquanto no modelo atual se utiliza o desmame precoce (menos de 21 dias), ou a modificação de níveis nutricionais de fêmeas, possibilitando que leitões nasçam com peso elevado, e que as fêmeas tenham lactações com satisfatórios volumes de leite.

Baseando-se nos resultados obtidos nos EUA e em diversos países, iniciou-se a adaptação do sistema para a realidade brasileira, pois um sistema idêntico ao americano não se mostrou viável, tanto econômico quanto tecnicamente, principalmente por dois motivos: a realidade produtiva nacional (clima, sanidade, nutrição, mão-de-obra, entre outros fatores) diferente da norte-americana; e a inviabilidade de investir em instalações conforme o padrão americano.

Entre as adaptações necessárias, percebeu-se a necessidade de aumentar o peso dos leitões no momento do desmame, através do aumento no período de lactação (passando a ser de 28 dias) e de novos conceitos na nutrição de matrizes. Mas ainda é necessário adaptar diversos aspectos técnicos até chegar-se ao modelo ideal de Wean to finish a ser implantado no Brasil e por isto, a pesquisa é um importante aliado na busca por melhores práticas e resultados.

O objetivo desse trabalho foi avaliar a viabilidade técnica de fornecer ração e água para leitões na maternidade, e a influencia desta prática no desempenho dos leitões durante a fase de lactação e fases subsequentes. 


\section{REFERENCIAL TEÓRICO}

A suinocultura tem importância econômica e social, pois representa garantia de renda para os produtores e para as nações, além de garantir proteína animal de qualidade para a sociedade contemporânea. De acordo com Rodrigues (2009), a carne suína é a mais consumida em todo o mundo e, nos últimos oito anos apresentou um crescimento médio de $14,6 \%$, e também é a carne mais produzida, apresentando no mesmo período um aumento médio na produção de $14,8 \%$.

A suinocultura no Brasil consolidou-se com a implantação da indústria frigorífica e com o surgimento da ABCS (Associação Brasileira de Criadores de Suínos), onde se intensificou a assistência técnica e a produção de chegou ao seu status atual, com boas condições de higiene e rigoroso controle sanitário.

A suinocultura moderna se apóia sobre seis alicerces: genética, nutrição, instalações, sanidade, manejo e práticas ambientalmente corretas, além de possuir uma cadeia produtiva que envolve diversos segmentos da sociedade, como, criadores, indústrias, distribuidores e consumidores.

A forma em que a produção suinícola está estruturada, também, conhecida como sistema de produção, é uma das áreas que oferecem espaço para se trabalhar melhorias e com algumas modificações, pode-se ampliar significativamente a rentabilidade da atividade. Para isso é necessário conhecer os principais sistemas produtivos praticados e também os que estão surgindo.

\section{DIFERENTES SISTEMAS DE PRODUÇÃO EM SUINOCULTURA}

Desde que a suinocultura passou a ser desenvolvida como uma atividade agroindustrial e geradora de renda, a mesma evoluiu em todos os setores. Pode-se afirmar que a genética melhorou, a nutrição teve uma significativa evolução e constantemente estão surgindo novas tecnologias que melhoram a 
WINCK, C.A. e GODOY, C.L. Viabilidade do fornecimento de água e ração para leitões em lactação no sistema Wean to finish. PUBVET, Londrina, V. 7, N. 16, Ed. 239, Art. 1581, Agosto, 2013.

sanidade e as instalações, visando à facilidade de manejo e o bem estar dos animais.

Os sistemas de produção também evoluíram e essas mudanças geralmente aconteceram para superar dificuldades. Atualmente existem vários sistemas de criação de suínos, sendo os principais: Ciclo completo; Sistema em dois sítios (iniciador + terminador); Sistema em três sítios (iniciador + crecheiro + terminador); e sistema Wean-to-finish. (Figura 1).

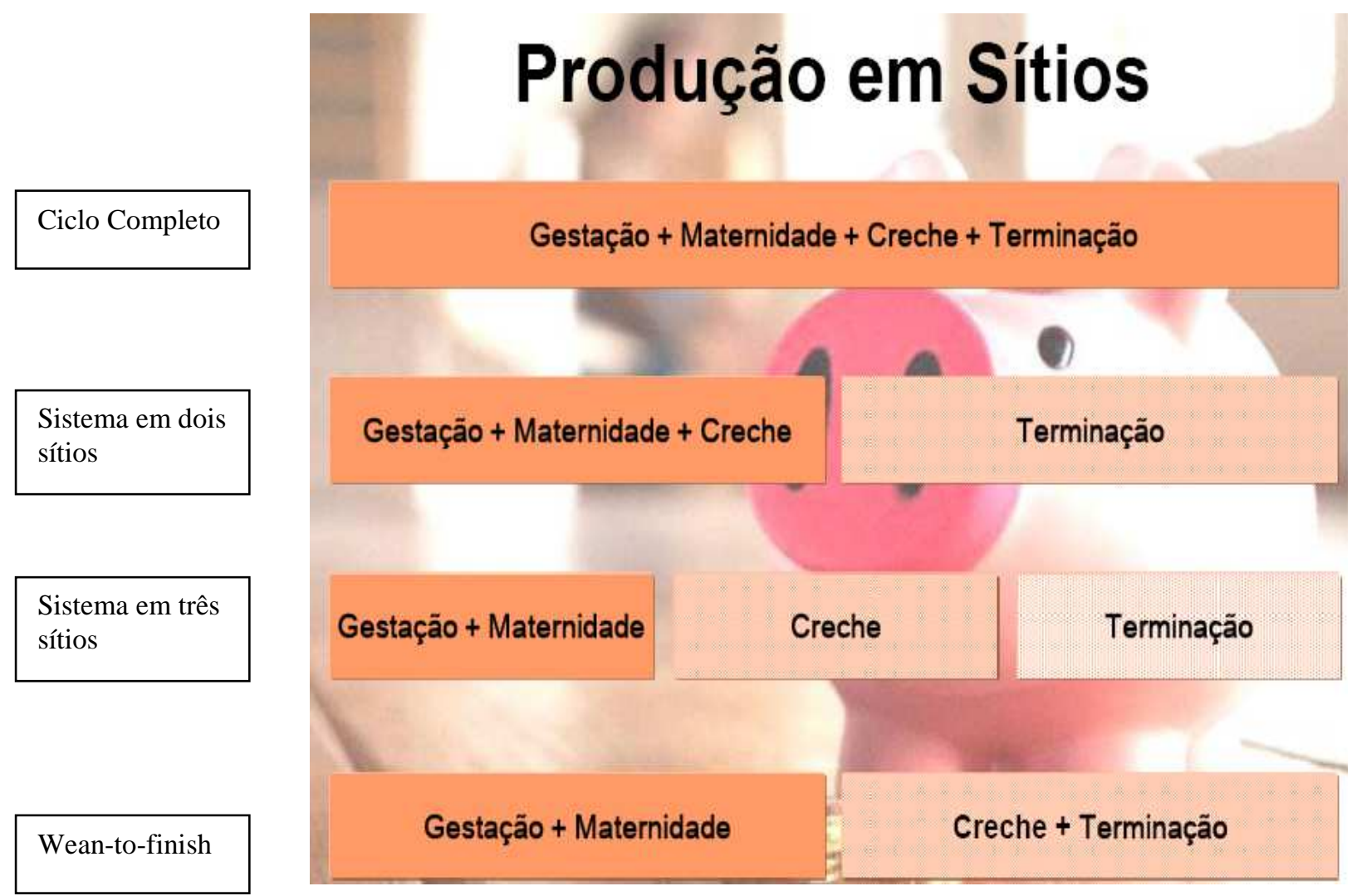

Figura 1: Caracterização dos sistemas de produção utilizados na produção de suínos. Fonte: adaptado com base em Heck (2009). 
WINCK, C.A. e GODOY, C.L. Viabilidade do fornecimento de água e ração para leitões em lactação no sistema Wean to finish. PUBVET, Londrina, V. 7, N. 16, Ed. 239, Art. 1581, Agosto, 2013.

\section{Ciclo completo}

O ciclo completo é um sistema de produção que, conforme afirma Sobestiansky et al. (1998, p. 19), "é uma criação que abrange todas as fases da produção e que tem como produto o suíno terminado, pronto para o abate".

De acordo com Hekc (2009), esse modelo é o mais antigo e tradicional, mas vem se reduzindo a sua utilização, devido aos problemas causados pelas constantes crises econômicas mundiais, e onde todo o capital utilizado na produção, geralmente é do proprietário. Esse modelo possui forte pressão sanitária, por trabalhar com fluxo contínuo e, consequentemente tem maiores problemas sanitários. Como pontos positivos podem-se citar a otimização da mão-de-obra e a concentração de todas as fases de produção.

Sistema de produção em dois sítios

Como o nome sugere, esse sistema é formado por dois sítios, ou seja, duas granjas. É o modelo mais utilizado atualmente no Brasil e no mundo.

O primeiro sítio é conhecido como unidade produtora de leitões ou iniciador, e para Sobestiansky et al. (1998, p. 20), "é aquela criação que envolve basicamente a fase de reprodução e tem como produto final os leitões", estando dividido em três setores: gestação, maternidade e creche.

Os leitões são amamentados por um período de aproximadamente 21 dias e, ao serem desmamados, são transferidos para uma instalação conhecida como creche, localizada na mesma propriedade. $\mathrm{Na}$ creche os leitões permanecem até aproximadamente 70 dias de vida, e quando atingem em média 23 quilos, os animais são transferidos para uma granja de terminação.

Na granja de terminação ou engorda, os leitões são alojados com 23 quilos (em média) e permanecem nesse local até atingir o peso final entre 100 a 135 quilos, e com idade entre 90 e 120 dias. Essa granja possui menor custo com instalações, pois os animais são alojados em baias coletivas (10 a 100 animais) e o sistema de arraçoamento é simples podendo ser manual ou automático. 
Geralmente a fase da terminação é verticalizada, ou seja, a agroindústria envia os leitões, a ração, os medicamentos e a assistência técnica, enquanto que o produtor oferece a mão-de-obra e as instalações, recebendo uma porcentagem pelos resultados atingidos.

Sistema de produção em três sítios

Neste sistema, a produção de suínos ocorre em três granjas distintas, sendo um sistema muito parecido com o anterior. Porém a fase de creche ocorre separada da granja produtora de leitões.

O primeiro sítio continua sendo conhecido como iniciador ou UPL (Unidade Produtora de Leitões), mas que "tem como produto o leitão desmamado, que pode ter em média $6 \mathrm{~kg}$ (21 dias) a $10 \mathrm{~kg}$ (42 dias)". (SOBESTIANSKY et al. 1998, p. 20).

A novidade, quando comparado ao sistema em dois sítios, é a fase intermediária, conhecida como creche, que ocorre em um local separado dos demais. Segundo Heck (2009) é um sistema menos corriqueiro, que necessita de mão-de-obra especializada; instalações adequadas, principalmente no que diz respeito à climatização; frota de transporte adaptada; e nutrição multifase, com dietas complexas.

Os leitões são alojados com peso entre 6 a $8 \mathrm{~kg}$ e idade entre 21 e 28 dias e são retirados com peso entre 18 a $28 \mathrm{~kg}$ e idade entre 56 a 70 dias. Após a retirada dos leitões do crechário, os mesmos são alojados em sítios com instalações de terminação, e o processo passa a ser idêntica a fase de engorda no sistema de produção em dois sítios.

\section{Wean to Finish}

O sistema de produção de suínos Wean to finish ainda é pouco conhecido no país. Conforme Heck (2009), é um sistema novo, utilizado como padrão nos Estados Unidos, mas que ainda está iniciando no Brasil.

O sistema consiste basicamente em um sistema de dois sítios, porém a fase de creche deixa de ser realizada na granja iniciadora. A fase reprodutiva 
ocorre em instalações idênticas as comumente utilizadas. No entanto, o fator que torna o sistema diferente é a adaptação de tecnologias para que o leitão permaneça do desmame ao abate em uma mesma instalação combinada. (YACENTIUK, 2010).

O Wean to finish foi desenvolvido nos Estados Unidos na década de 90. Conforme Firkins, (1998, p.1) "O conceito de Wean to finish é contrária à crença de que os suínos de creche e terminação exigem instalações exclusivas para cada fase da produção". Este conceito é muito parecido com o utilizado na produção de aves.

Segundo Firkins (1998), a proposta de beneficio desse novo sistema é a eliminação do stress de deslocamento e reagrupamento dos suínos. Algumas pesquisas demostram que cada vez que um suíno é transportado, o mesmo atrasa seu desenvolvimento em até 7 dias, aumentando o tempo de alojamento até estar pronto para o abate.

Com o aprimoramento do sistema, outros benefícios foram percebidos em diversos países. Na experiência chilena de implantação, perceberam-se as seguintes vantagens (PERALTA, 2008):

- Menor custo com transporte de animais, pois os mesmos são transportados somente uma vez durante a vida, e enquanto são pequenos e leves, otimizando a carga do veículo;

- Menor custo com limpeza e desinfecção e menor número de dias vazios do que um sistema convencional, devido a não ser necessário lavar e desinfetar as instalações no momento em que os leitões seriam transferidos para a creche;

- Menor mortalidade e maior número de suínos de qualidade superior;

- Menor conversão alimentar e maior ganho de peso diário (GPD), devido a uma significativa melhora no status sanitário dos animais, que se adaptam desde jovens em uma instalação, sem necessitar passar por diversos momentos de stress durante a vida.

Mas o novo sistema de criação de suínos também possui algumas desvantagens. Firkins (1998) cita as seguintes: 
- Uso ineficiente do espaço nas instalações, principalmente nos primeiros dias pós desmame, pois um leitão de aproximadamente $7 \mathrm{~kg}$ vai ocupar o mesmo espaço que no futuro será utilizado por um animal com mais de 100kg;

- Maior custo com o aquecimento das instalações, pois quanto mais jovens os animais, maior é a exigência com o conforto térmico;

- Dificuldade em encontrar equipamentos (bebedouros, comedouros entre outros), que se adaptem ao mesmo tempo para animais de $7 \mathrm{~kg}$ e para animais com mais de $100 \mathrm{~kg}$;

- Maior dificuldade em mover os animais durante o carregamento, pois os mesmos passaram toda a vida na mesma baia e, certamente, resistirão para sair.

Após realizar um balanço entre os pontos positivos e negativos, pode-se afirmar que o sistema é interessante tecnicamente e economicamente. Segundo Peralta (2008) em estudo realizado no Chile, o benefício médio foi de 1,40 dólares por suíno quando comparado a sistemas convencionais.

Um fator que leva a crer na viabilidade do Wean to finish é a situação atual da suinocultura norte-americana, uma das mais desenvolvidas e rentáveis do mundo. Segundo Piva e Kummer (2008) em 1992, mais de 65\% dos suínos eram produzidos em granjas de ciclo completo e em 2004, menos de $18 \%$ do rebanho suíno estava alojado desta forma, e isto se efetivou principalmente por motivos de ordem operacional e sanitária, permitindo o crescimento do Wean to finish em solo americano.

\section{WEAN TO FINISH: A EXPERIÊNCIA BRASILEIRA}

Como citado anteriormente, o sistema Wean to finish se mostrou muito interessante tanto por aspectos de ordem econômica quanto produtiva. Por isso, e seguindo o exemplo do Chile, o sistema americano vem sendo implantado na suinocultura brasileira, embora que já tenham ocorrido diversas tentativas frustradas de implantação do Sistema Wean to finish. 
O principal motivo pelo insucesso na implantação do sistema no Brasil deve-se a reduzida adaptação à realidade produtiva brasileira, principalmente nos aspectos clima, mão-de-obra, instalações e nutrição.

No ano de 2007, uma cooperativa localizada na região Meio-oeste do Estado de Santa Catarina, principal região de produção de suínos do Estado, iniciou o processo de mudanças para que o sistema Wean to finish se adaptasse à realidade da suinocultura regional.

Muitos conceitos sobre a suinocultura convencional tiveram que ser reformulados, e segundo Simioni (2008, p. 20) "Os técnicos também precisaram ir à contramão do que aprenderam [...] para a implantação do Wean to finish". As instalações tiveram que ser adaptadas, pois anteriormente recebiam animais com média de peso superior a $20 \mathrm{~kg}$, e comedouros e bebedouros adequados para animais leves tiveram que ser instalados.

Outra mudança significativa no que diz respeito às instalações de terminação foi a implantação de um sistema mais eficiente de aquecimento, pois os animais com peso médio de $7 \mathrm{~kg}$ e com idade média de 28 dias são muito vulneráveis a problemas sanitários oriundos do stress térmico, principalmente no que diz respeito ao frio. Conforme Sobestiansky et al. (1998), a temperatura de conforto para leitões com 4 semanas de vida é em torno de 25 a $28{ }^{\circ} \mathrm{C}$, e no inverno, a temperatura facilmente se situa abaixo desse valor no sul do país.

O manejo dos suínos também teve que ser revisto, pois os iniciadores, que até então eram acostumados a produzir animais com peso médio superior a $20 \mathrm{~kg}$ e com fase de creche, passaram a produzir leitões desmamados, e os terminadores tiveram que se adaptar a cuidar de leitões mais novos e, consequentemente, mais sensíveis.

No fator nutrição aconteceram diversas mudanças, pela necessidade de desmamar leitões mais pesados do que no sistema convencional, os conceitos de nutrição de matrizes foram alterados, visando produzir leitões com peso maior no nascimento e maior produção de leite durante a lactação. Como 
somente ajustes nutricionais não foram suficientes para solucionar essa necessidade o período de lactação foi aumentado.

De acordo com Simione (2008) o pico de produção de leite das fêmeas ocorre justamente no $21^{\circ}$ dia. No Wean to finish os leitões mamam mais e ganham em peso e sanidade (Figura 2). Este aspecto também foi identificado pelos pesquisadores americanos, Piva e Kummer (2008, p. 130) que afirmaram: "O sistema Wean to finish tem motivado ou, até certo ponto, forçado um aumento na idade e peso ao desmame, passando de 14 a 15 dias de lactação para 19 a 21 dias e, peso de desmame superior a 6 kg."

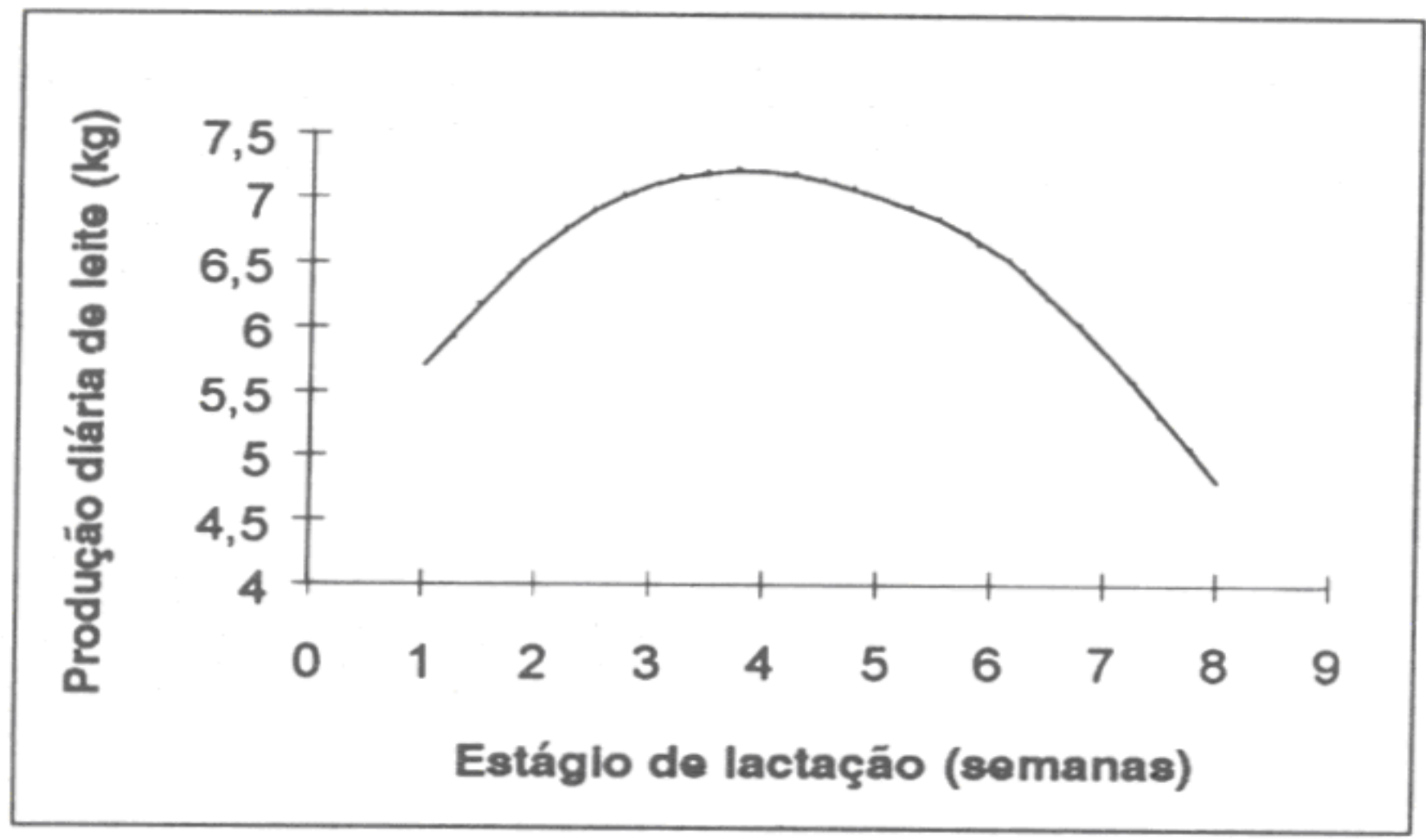

Figura 2: Efeito da duração da lactação sobre a produção de leite. Fonte: Sobestiansky, et al. 1998.

O diferencial com a realidade americana está no período de lactação, que passou para 28 dias em média e o peso de desmame que ultrapassa os $7,5 \mathrm{~kg}$. 
WINCK, C.A. e GODOY, C.L. Viabilidade do fornecimento de água e ração para leitões em lactação no sistema Wean to finish. PUBVET, Londrina, V. 7, N. 16, Ed. 239, Art. 1581, Agosto, 2013.

O sistema Wean to finish brasileiro vem alcançando resultados interessantes, que de certa forma vem viabilizando a prática da suinocultura. Nos momentos de mercado conturbado e até imprevisível, alguns resultados positivos alcançados são de ordem zootécnica como melhor GPD, menor mortalidade, menor incidência de doenças.

Avaliando-se a questão ambiental, o novo sistema utiliza menor quantidade de água e consequentemente produz um volume menor de dejetos. Quando avaliadas questões econômicas, o Wean to finish se mostra viável pois aumenta a rentabilidade da cadeia produtiva, remunerando melhor o produtor que utilizou menos capital de giro para produzir os suínos (Quadro 1).

Quadro 1: Comparativo entre o sistema convencional e Wean to finish no Brasil.

\begin{tabular}{|c|c|}
\hline $\begin{array}{l}\text { MODELO CONVENCIONAL } \\
\text { ( } 2 \text { sítios) }\end{array}$ & MODELO WEAN TO FINISH \\
\hline Idade desmame 21 dias. & Idade desmame 28 dias. \\
\hline Peso médio/leitão no desmame 6,1 kg. & Peso médio/leitão no desmame $8,1 \mathrm{~kg}$. \\
\hline $\begin{array}{l}\text { Peso médio/leitão na creche aos } 40 \text { dias de } \\
\text { idade } 20 \mathrm{~kg} \text { vivo. }\end{array}$ & $\begin{array}{l}\text { Peso médio/leitões aos } 40 \text { dias de idade } 25 \\
\text { kg vivo. }\end{array}$ \\
\hline $\begin{array}{l}\text { Idade necessária para atingir peso de abate } \\
115 \mathrm{~kg} \text { vivo }=160 \text { dias de vida. }\end{array}$ & $\begin{array}{l}\text { Idade necessária para atingir peso de abate } \\
115 \mathrm{~kg} \text { vivo }=140 \text { dias de vida. }\end{array}$ \\
\hline $\begin{array}{l}\text { Média de mortalidade nas terminações }= \\
4,02 \% \text {. }\end{array}$ & $\begin{array}{l}\text { Média de mortalidade nas terminações }= \\
2,04 \% \text {. }\end{array}$ \\
\hline $\begin{array}{l}\text { Necessita mão-de-obra especifica para setor } \\
\text { creche. }\end{array}$ & Não necessita de mão-de-obra específica. \\
\hline $\begin{array}{l}\text { Excessivo gasto de água com lavação de } \\
\text { creches e consequente maior produção de } \\
\text { dejetos. }\end{array}$ & $\begin{array}{l}\text { Diminuição na utilização de água e menor } \\
\text { produção de dejetos. }\end{array}$ \\
\hline $\begin{array}{l}\text { Maior capital de giro investido para produção } \\
\text { de leitões. }\end{array}$ & $\begin{array}{l}\text { Menor capital de giro para produção } \\
\text { leitões. }\end{array}$ \\
\hline $\begin{array}{l}\text { Incidência maior de doenças na } \\
\text { Creche. }\end{array}$ & Menor incidência de doenças. \\
\hline Rentabilidade menor. & Rentabilidade maior. \\
\hline
\end{tabular}

Fonte: Cooperativa A (2008).

Experiências foram realizadas visando definir às melhores praticas para a efetivação do Wean to finish brasileiro, porém, como não é possível utilizar resultados vistos como ideais para os outros sistemas, muitos 
WINCK, C.A. e GODOY, C.L. Viabilidade do fornecimento de água e ração para leitões em lactação no sistema Wean to finish. PUBVET, Londrina, V. 7, N. 16, Ed. 239, Art. 1581, Agosto, 2013.

questionamentos ainda devem ser postos em teste para chegar-se à metodologia ideal. Tem-se como uma das certezas a necessidade de desmamar leitões mais pesados, aumentando o período de lactação afetando também os conceitos sobre nutrição de matrizes.

Falta mensurar ainda a eficiência e rentabilidade de suplementação com ração para leitões durante a fase de lactação, para saber se essa prática aumenta o peso de desmame ou influencia no desempenho desses leitões na próxima fase.

\section{FORNECIMENTO DE RAÇÃO PARA LEITÕES DURANTE A FASE DE LACTAÇÃO}

Para discutir a viabilidade de fornecer ração para leitões durante a fase de lactação, é importante conhecer dois aspectos relacionados diretamente com o assunto, sendo eles: a produção de leite da fêmea em condições adequadas e a necessidade alimentar dos leitões.

O período de lactação inicia ao parto. Nessa fase a fêmea deve produzir leite suficiente, objetivando uma alta taxa de crescimento de tantos leitões quanto forem possíveis, obtendo-se peso ao desmame compatível com a viabilidade econômica do processo. (SILVEIRA et al., 1998).

Segundo Dias; Meincke; Souza (2005, p. 41) "um ponto que deve ser entendido é a curva de lactação da fêmea, que é ascendente até a terceira semana". Em sistemas de manejos convencionais é justamente nessa idade que os leitões são desmamados, não aproveitando a produção de leite justamente quando a mesma vai atingir seu pico. (Figura 2).

Do nascimento até as cinco primeiras semanas de vida dos leitões, as secreções digestivas diferem muito em concentração e atividade do que as de um suíno adulto (MORES et al.,1998). Estudos realizados em leitões têm indicado que tanto o $\mathrm{HCl}$ como a pepsina têm pouca participação digestiva até que os leitões alcancem 3 a 4 semanas de idade (ANDRIGUETTO et al., 1983), e isto significa que, em alguns momentos dessa fase, os leitões ainda não estão aptos para digerir alimentos de origem vegetal. 
Durante os primeiros 21 dias de vida, as necessidades nutritivas da leitegada são preenchidas pela produção leiteira da porca, e a partir deste período, aumentam progressivamente as necessidades nutritivas dos leitões. (SOBESTIANSKY et al., 1985). Portanto, a crescente demanda em nutrientes pelos leitões, pode ser suprida por meio de fornecimento de uma ração suplementar (MORES, 1998).

Para Dias; Meincke; Souza (2005, p. 43), "recomenda-se o fornecimento de ração pré-inicial de alta digestibilidade, $[. .$.$] em pequenas quantidades a$ partir do décimo dia de vida." Porém, conforme Andriguetto (1983, p. 130) "Por outro lado, a diarréia [...] pode resultar de mudança na flora bacteriana intestinal, provocada pela ingestão de alimentos sólidos ."

A finalidade de fornecer a primeira ração é suprir as necessidades nutritivas da leitegada, favorecendo o crescimento dos leitões mais fracos em leitegadas muito grandes e acostumar os leitões a comerem um alimento sólido e seco antes do desmame, para evitar o stress do desmame sem essa adaptação. (MORES et al. 1998).

\section{PROCEDIMENTOS METODOLOGICOS}

O experimento de campo foi realizado no departamento de suinocultura da Cooperativa "A", pioneira no sistema Wean to Finish no Brasil, mais especificamente em três granjas produtoras de leitões, onde foi realizada a primeira etapa do experimento, e duas granjas de terminação onde foi realizada a segunda etapa.

Esta cooperativa possui 40 anos de história e sua matriz fica localizada no município de Joaçaba, no Meio Oeste catarinense, e atua também em mais de 70 municípios localizados nas regiões Meio-oeste, Sul, Planalto Serrano e Planalto Norte de Santa Catarina, e ainda na região Norte do Rio Grande do Sul. Possui aproximadamente 7.000 cooperados e 450 funcionários.

A suinocultura é a principal atividade da Cooperativa " $A$ ", produzindo aproximadamente 40.000 suínos terminados por mês. Além dos suínos, possui 
entre outras atividades: 38 lojas agropecuárias, uma UBF (unidade de beneficiamento de sementes), 20 unidades de recebimento e armazenagem de grãos com capacidade para 1.700 .000 sacas, duas fabricas de ração; dois postos de resfriamento de leite, um campo de recria de terneiras e um laticínio.

\section{PRIMEIRA ETAPA DO EXPERIMENTO}

As três granjas escolhidas para a realização do experimento trabalham no sistema Wean to Finish desde 2009, com desmame aos 28 dias de lactação, possuem a mesma linhagem genética e consomem ração com níveis nutricionais idênticos, produzida na fabrica de rações de Joaçaba-SC.

A granja "A" está localizada no município de Luzerna-SC, possuindo 1.700 matrizes alojadas, e onde foram realizadas cinco amostragens por tratamento, e uma repetição do experimento três semanas após a primeira.

A granja "B" possui 500 matrizes alojadas, e está localizada no município de Água Doce-SC, e onde foram realizadas 3 amostragens por tratamento. A granja " $C$ " com 500 matrizes alojadas, localiza-se no município de Xanxerê-SC, onde foram realizadas 3 amostragens por tratamento.

O experimento de campo considerou que cada amostra correspondeu a uma leitegada, e foi realizado durante o segundo semestre de 2009 e o primeiro semestre de 2010, utilizando-se leitegadas que nasceram na mesma semana e que foram submetidas a quatro tratamentos diferentes:

- Tratamento "A+R" (Água + Ração), os leitões tiveram água disponível em bebedouros tipo taça desde o nascimento até o desmame e a partir do décimo dia de vida receberam ração indicada para a fase que foi fornecida em comedouros próprios para a idade. Esta ração foi oferecida para os animais 6 vezes ao dia, sendo três vezes pela manha e três a tarde com o intuito que os animais tivessem sempre ração à vontade porém sem desperdício, até o momento do desmame; 
- Tratamento "R" (Ração), os leitões receberam, a partir do décimo dia de vida, ração indicada para a fase que foi fornecida em comedouros próprios para a idade, essa ração foi oferecida para os animais 6 vezes ao dia sendo três pela manha e três a tarde com o intuito que os animais tivessem sempre ração à vontade porem sem desperdício, mas não receberam água, somente leite materno;

- Tratamento "A" (Água), os leitões receberam somente água que estava disponível em bebedouros tipo taça desde o nascimento até o desmame, mas não receberam ração;

- Tratamento "N" (Nada), os leitões não receberam nem água nem ração durante a fase de lactação, somente leite materno.

O teste iniciou-se com a pesagem da leitegada, que ocorreu logo após a uniformização pós-parto dos leitões. Estas leitegadas possuíam peso médio aproximado e nasceram no mesmo dia. Após a pesagem, iniciava-se o acompanhamento diário, onde um profissional observava e anotava a mortalidade relacionada à alimentação, como as causadas por diarréias ou por inanição, e a ocorrência de diarréias, atribuindo uma nota pela intensidade da mesma, sendo:

Nota 0: leitegadas sem diarreia;

Nota 1: leitegadas com diarreia persistente por no máximo dois dias;

Nota 2: leitegadas onde a diarréia persistiu por mais de três dias.

$\mathrm{Na}$ data do desmame essas leitegadas foram pesadas e posteriormente, com o auxilio das anotações diárias, foram calculados: Ganho de Peso Diário (GPD), porcentagem de mortes e ocorrência de diarréias.

\section{SEGUNDA ETAPA DO EXPERIMENTO}

A segunda etapa do experimento iniciou após desmame dos leitões que participaram da primeira etapa experimental na Granja Luzerna. Foram escolhidos 50 leitões de cada um dos tratamentos, "A+R", "A", "R", "N", sendo 25 na primeira repetição e 25 na segunda. 
Os animais foram transferidos para instalações onde ocorre a segunda fase do Wean to finish "creche/terminação", seguindo o cronograma de alojamento da Cooperativa. A primeira metade dos leitões foi alojada no município de Treze Tílias-SC, na granja de um cooperado, e a segunda metade foi alojada no município da Água Doce-SC, na granja de outro produtor cooperado.

Inicialmente cada leitão recebeu um brinco com numeração individual e chegando à instalação de terminação, os animais eram pesados individualmente em balança eletrônica de precisão. Os leitões do experimento receberam tratamento idêntico aos demais alojados na instalação. A pesagem foi repetida 30 dias após a primeira, para mensurar o desempenho inicial dos animais logo após o desmame.

No final dos 30 dias foi calculado o Ganho de Peso Diário (GPD), com o intuito de constatar se os leitões que receberam suplementação nutricional durante a lactação possuem maior peso ao iniciarem à próxima fase. É importante salientar que alguns leitões não foram pesados no final do experimento devido a queda de alguns brincos, porém, todos os que ofereceram condição de executar a pesagem foram considerados.

Os dados obtidos no experimento foram analisados pelo pacote estatístico SAS, utilizando-se analise de variância e teste de Tukey à $5 \%$.

\section{RESULTADOS E DISCUSSÃO}

Os resultados obtidos durante os experimentos de campo estão representados nas tabelas que seguem, e deve-se considerar que estes apontam um caminho a seguir, mas tendo a compreensão que se faz necessário, a continuidade da pesquisa, melhorando assim o entendimento e a busca pelo aperfeiçoamento do Sistema Wean to Finish como alternativa produtiva. 
$\mathrm{Na}$ Tabela 1, apresentam-se os dados iniciais das leitegadas com a intenção de demonstrar que não ocorreu diferença estatística significativa entre os aspectos que poderiam influenciar no desempenho futuro dos animais.

A ordem de parto (número de vezes que a porca pariu, incluindo o parto atual), é importante de ser avaliada, pois existem diferenças qualitativas e quantitativas na produção de leite pelas porcas, oscilando conforme o número de partos, sendo que a quantidade produzida segue uma crescente até cinco partos, porém a qualidade nutricional do leite decresce em fêmeas mais velhas. Nas leitegadas utilizadas no experimento, não ocorreram diferenças estatísticas significativas, eliminando-se assim, essa variável que poderia interferir negativamente no processo.

$\mathrm{O}$ número médio de leitões por leitegada deve ser considerado, pois o numero de tetos nas porcas lactantes é limitado, oscilando entre 6 a 8 pares, com isso pequenas leitegadas podem ser favorecidas e leitegadas com muitos leitões podem ser prejudicadas, sendo que o experimento realizado não apresentou diferença estatística entre as 64 leitegadas.

O peso ao nascimento foi avaliado, pois leitões mais pesados apresentam maior vigor, e consequentemente possuem capacidade de mamar quantidades maiores de leite, enquanto que leitões menores tendem a mamar menos, baixando seu desempenho e aumentando inclusive a taxa de mortalidade. $\mathrm{O}$ peso ao nascimento não apresentou diferença estatística significativa nesse experimento.

Tabela 1: Comparação entre tratamentos considerando características iniciais das leitegadas.

\begin{tabular}{cccc}
\hline Tratamentos & Ordem Parto & $\mathbf{N}^{\circ}$ Leitões & Peso ao Nascimento \\
\hline $\mathbf{A}+\mathbf{R}$ & $3,31^{\mathrm{a}}$ & $12,00^{\mathrm{a}}$ & $1,65^{\mathrm{a}}$ \\
$\mathbf{A}$ & $3,50^{\mathrm{a}}$ & $12,13^{\mathrm{a}}$ & $1,56^{\mathrm{a}}$ \\
$\mathbf{R}$ & $3,18^{\mathrm{a}}$ & $11,82^{\mathrm{a}}$ & $1,64^{\mathrm{a}}$ \\
$\mathbf{N}$ & $3,63^{\mathrm{a}}$ & $11,63^{\mathrm{a}}$ & $1,62^{\mathrm{a}}$ \\
\hline
\end{tabular}

Médias seguidas de mesma letra na vertical não diferem entre si pelo teste de Tukey a $5 \%$. 
A Tabela 2 apresenta os resultados obtidos na data de desmame (28 dias aproximadamente) com a pesagem final das leitegadas, considerando peso final, ganho de peso total, GPD, ocorrência de diarréia e mortalidade.

$O$ peso final variou $0,220 \mathrm{~kg}$ do menor $(7,61 \mathrm{~kg}$ no tratamento somente com ração) para o maior ( $7,83 \mathrm{~kg}$ no tratamento Água + Ração), e analisandose pelo teste Tukey a $5 \%$, não ocorreu diferença estatística entre todos os tratamentos estudados. As variáveis ganho de peso (peso que os leitões ganharam até o desmame), e ganho de peso diário (GPD), também não apresentaram diferença significativa entre as média obtidas.

A ocorrência de diarréia não apresentou diferença estatística entre os quatro tratamentos. A mortalidade, por causas relacionadas à alimentação como diarréia ou inanição, não apresentou diferença entre os tratamentos, e especificamente neste experimento, a produção de leite das fêmeas mostrouse suficiente para a manutenção da vida dos leitões.

Tabela 2: Comparação entre tratamentos considerando características finais das leitegadas.

\begin{tabular}{cccccc}
\hline Tratamentos & Peso Final & Ganho de Peso & GPD & Diarreia & Mortalidade \\
\hline $\mathrm{A}+\mathrm{R}$ & $7,83^{\mathrm{a}}$ & $6,18^{\mathrm{a}}$ & $0,229^{\mathrm{a}}$ & $0,56^{\mathrm{a}}$ & $0,25^{\mathrm{a}}$ \\
$\mathrm{A}$ & $7,69^{\mathrm{a}}$ & $6,13^{\mathrm{a}}$ & $0,227^{\mathrm{a}}$ & $0,38^{\mathrm{a}}$ & $0,13^{\mathrm{a}}$ \\
$\mathrm{R}$ & $7,61^{\mathrm{a}}$ & $5,97^{\mathrm{a}}$ & $0,225^{\mathrm{a}}$ & $0,68^{\mathrm{a}}$ & $0,25^{\mathrm{a}}$ \\
$\mathrm{N}$ & $7,70^{\mathrm{a}}$ & $6,09^{\mathrm{a}}$ & $0,221^{\mathrm{a}}$ & $0,44^{\mathrm{a}}$ & $0,37^{\mathrm{a}}$ \\
\hline
\end{tabular}

Médias seguidas de mesma letra na vertical não diferem entre si pelo teste de Tukey a $5 \%$.

$\mathrm{Na}$ Tabela 3, apresentam-se os resultados da segunda etapa do experimento, onde se considerou o desempenho dos leitões nos primeiros 30 dias após o desmame. Nesta fase, o fato de os leitões já terem contato com comedouros e bebedouros, deveria possibilitar um melhor desempenho, considerando peso final e GPD. 
WINCK, C.A. e GODOY, C.L. Viabilidade do fornecimento de água e ração para leitões em lactação no sistema Wean to finish. PUBVET, Londrina, V. 7, N. 16, Ed. 239, Art. 1581, Agosto, 2013.

Tabela 3: Comparação entre tratamentos considerando características finais dos leitões 30 dias pós desmame.

\begin{tabular}{cccc}
\hline Tratamentos & Peso Final & Ganho de Peso & GPD \\
\hline $\mathrm{R}$ & $17,31^{\mathrm{a}}$ & $9,67^{\mathrm{a}}$ & $0,32^{\mathrm{a}}$ \\
$\mathrm{N}$ & $17,36^{\mathrm{a}}$ & $9,78^{\mathrm{ab}}$ & $0,32^{\mathrm{ab}}$ \\
$\mathrm{A}+\mathrm{R}$ & $18,02^{\mathrm{a}}$ & $9,86^{\mathrm{ab}}$ & $0,33^{\mathrm{ab}}$ \\
$\mathrm{A}$ & $18,22^{\mathrm{a}}$ & $10,96^{\mathrm{b}}$ & $0,36^{\mathrm{b}}$ \\
\hline
\end{tabular}

Médias seguidas de mesma letra na vertical não diferem entre si pelo teste de Tukey a $5 \%$.

Nos resultados obtidos no experimento não se encontrou diferença estatística significativa entre os tratamentos, exceto quando comparando o grupo que recebeu somente Ração (R) com o grupo que recebeu somente água (A). Com isto, percebeu-se que os animais que tinham acesso a água $(A+R$; A), conseguiram melhor peso final, maior ganho de peso e maior GPD, do que animais que não receberam água durante o experimento $(R ; N)$.

Considerando-se os pesos finais entre tratamentos, embora não tenha ocorrido diferença estatística, os animais que não receberam água, (Ração (R) e $\operatorname{Nada}(\mathrm{N})$ ), atingiram após 30 dias, um peso de $17,31 \mathrm{~kg}$ e $17,36 \mathrm{~kg}$ respectivamente, e os animais que receberam água, (Água + Ração $(A+R)$ e Água (A), atingiram respectivamente os pesos de $18,02 \mathrm{~kg}$ e $18,22 \mathrm{~kg}$, o que confere um incremento de aproximadamente $0,700 \mathrm{~kg}$ entre os grupos com e sem acesso a água.

Baseando-se nas constatações obtidas pela tabela anterior surgiu a necessidade de avaliar os resultados de outra forma, desconsiderando o fornecimento de ração, e dividindo os animais em dois grupos, os que tiveram acesso a água durante a fase de lactente e os leitões que não tiveram esse acesso.

A Tabela 4 comprova que, mesmo não havendo diferença estatística no peso ao desmame dos animais, os leitões que tiveram acesso a água alcançaram índices melhores durante o inicio da próxima fase do Wean to finish "creche/terminação", considerando o ganho de peso da fase que foi de $10,48 \mathrm{~kg}$ para animais que tiveram contato com a água e de $7,71 \mathrm{~kg}$ para animais que não tiveram, e o GPD que foi de $0,349 \mathrm{~kg}$ e $0,323 \mathrm{~kg}$ 
WINCK, C.A. e GODOY, C.L. Viabilidade do fornecimento de água e ração para leitões em lactação no sistema Wean to finish. PUBVET, Londrina, V. 7, N. 16, Ed. 239, Art. 1581, Agosto, 2013.

respectivamente. Ambos os índices apresentaram diferença estatística significativa analisando-se pelo teste Tukey a $5 \%$.

Tabela 4: Comparação entre tratamentos com ou sem suplementação com água, considerando aspectos zootécnicos após 30 dias do desmame.

\begin{tabular}{lcccc}
\hline & Peso ao desmame & Peso Final & Ganho de Peso & GPD \\
\hline Com Água & $7,66 a$ & $18,14 a$ & $10,48 b$ & $0,349 b$ \\
Sem Água & $7,61 a$ & $17,33 a$ & $9,71 a$ & $0,323 a$ \\
\hline
\end{tabular}

Médias seguidas de mesma letra na vertical não diferem entre si pelo teste de Tukey a $5 \%$.

Possivelmente isto ocorreu por que a água $\left(\mathrm{H}_{2} \mathrm{O}\right)$ é um alimento importante para a manutenção da vida, mas que não agrega nutrientes para a melhoria da qualidade da dieta, então o que pode explicar esta diferença de peso, supostamente seja o fato de que na chegada à nova instalação, os animais já conheciam o funcionamento do bebedouro, e com isto consumiram água com mais facilidade, melhorando a deglutição da ração e aumentando assim o consumo da mesma.

Leitões que ainda não haviam tido contato com o bebedouro durante o período de maternidade, precisaram aprender a utilizá-lo, reduzindo-se assim o ganho de peso inicial, podendo provocar inclusive, uma considerável perda de peso.

\section{CONCLUSÕES}

Na primeira etapa do experimento, levando-se em consideração somente a fase de leitões lactentes até os desmame, não ocorreram diferenças estatísticas significativas em nenhum dos índices avaliados: ganho de peso, GPD, ocorrência de diarréias e ocorrência de mortalidade. Pode se concluir que há indícios de que o fornecimento de suplementação nutricional durante a fase de lactação é não é viável, pois o investimento em equipamentos e ração, foi desnecessário. 
WINCK, C.A. e GODOY, C.L. Viabilidade do fornecimento de água e ração para leitões em lactação no sistema Wean to finish. PUBVET, Londrina, V. 7, N. 16, Ed. 239, Art. 1581, Agosto, 2013.

Deve-se ressaltar que o experimento foi realizado em um curto espaço de tempo, e que o ideal para obter conclusões definitivas e mais concretas, seria repetir o experimento em outras condições climáticas, nutricionais e sazonais. Sabe-se que a sazonalidade interfere diretamente na qualidade e quantidade da ração consumida pela porca, e diretamente na produção de leite. Em casos de baixa produção de leite a suplementação com ração pode suprir eventuais déficits nutricionais dos leitões.

$\mathrm{Na}$ segunda etapa do experimento, avaliando o desempenho dos animais durante os 30 primeiros dias após o desmame, conclui-se que não se apresentou diferença estatística considerável entre os leitões que foram submetidos, durante a fase de lactentes, aos quatro tratamentos $(A+R, R, A$ e $\mathrm{N})$, porém quando separadas as fontes de suplementação, água ou ração, percebe-se que os leitões que tiveram contato com o bebedouro de água durante a lactação, apresentaram diferença estatística significativa e superior aos que não tiveram este contato inicial. Possivelmente, isto ocorreu pelo motivo de os leitões já conhecerem o modelo dos bebedouros e por consequência, adaptaram-se mais rapidamente à nova instalação, iniciando o consumo de ração mais rapidamente.

\section{REFERÊNCIAS}

ANDRIGUETTO, José Milton et al. Suínos. In: ANDRIGUETTO, José Milton et al. Nutrição animal - Alimentação animal (Nutrição animal aplicada).São Paulo, AMPUB Comercial Ltda., 1983. cap. 2, p. 130.

CoOperativa A. Premio cooperativa do ano. Disponível em:

<http://www.cooperativa.com.br>. Acesso em: 26 de agosto de 2012.

DIAS, Cleandro Pazinato; MEINCKE, Werner; SOUZA, Ana Lúcia Pozzobon de. Nutrição de leitões: do leite a ração. Revista Suinocultura Industrial, edição 188, n. 5, p. 40 - 43, 2005.

FIRKINS, Lawrencw D. Wean-to-Finish Buildings. 1 jan. 1998. Disponível_em: $<$ http://www.livestocktrail.uiuc.edu/porknet/paperDisplay.cfm?ContentID $=679$ >. Acesso em: 26 ago 2012.

HECK, Augusto. Atualização sobre os sistemas de produção em suinocultura: pontos críticos e impactos sobre a produção. In: SHAPING THE FUTURE, 2009, São Paulo. Anais eletrônicos, 2009. CD-ROM. 
HISTÓRIA dos Suínos. Disponível em: <http://www.abcs.org.br/portal// mun_sui/produção/genetica/historia.jsp>. Acesso em: 9 set 2009.

HISTÓRICO da Suinocultura. Disponível em: < http://www.accs.org.br/ >. Acesso em: 9 set 2012.

MORES, Nelson et al. Manejo do leitão desde o nascimento até o abate. In: SOBESTIANSKY, Jurij et al. Suinocultura intensiva - Produção, Manejo e Saúde do Rebanho. Brasília:

Embrapa, 1998. cap. 7, p.135 - 162.

PERALTA, Wolfgang. Sistema destete venta em Chile. Acta Scientiae Veterinariae, Porto Alegre, p. 131 - 136, 2008. Disponível em: <http://www.ufrgs.br/favet/revista>. Acesso em: 4 ago 2009.

PIVA, Jose Henrique; KUMMER Rafael. Análise da suinocultura dos Estados Unidos da América. Acta Scientiae Veterinariae, Porto Alegre, p. 125 - 130, 2008. Disponível em: <http://www.ufrgs.br/favet/revista>. Acesso em: 4 ago 2012.

RODIGHERI, Julio Alberto.Desempenho da carne suína em 2007 e perspectivas para 2008 Síntese Anual da Agricultura de Santa Catarina 2007 - 2008, Florianópolis, Epagri, $174-181,2008$.

SILVEIRA, Paulo R. S. da et al. Manejo da fêmea reprodutora. In: SOBESTIANSKY, Jurij et al. Suinocultura intensiva - Produção, Manejo e Saúde do Rebanho. Brasília: Embrapa, 1998. cap. 8, p.163 - 196.

SIMIONI, Lílian. Suinocultura com maior rentabilidade - Cooperativa adota novo sistema de produção que revoluciona a criação. Diário Catarinense, Joaçaba, 14 jul. 2008. Campo e Lavoura, p. 20.

SOBESTIANSKY, Jurij et al. Manejo em Suinocultura - Aspectos Sanitários, Reprodutivos e de Meio Ambiente. Concordia: Embrapa, 1985. 184p.

SOBESTIANSKY, Jurij et al. Suinocultura Intensiva - Produção, Manejo e Saúde do Rebanho. Brasília: Embrapa, 1998. 388p.

YACENTIUK, Mike. Wean to Finish Concept Attracting Attention. 2010. Disponível em: <http://www.gov.mb.ca/agriculture/livestock/pork/ bab02s06.html>. Acesso em: 26 ago 2012. 